\title{
An Extra Chromosomal Centric Fragment in an Infant with Stigmata of Down's Syndrome
}

\author{
I. ŠUBRT and HELENA PRCHLfKOVÁ
}

\author{
From the Department of Paediatrics, Faculty of Medical Hygiene, Charles University, Prague, Czechoslovakia
}

The occurrence of an extra chromosomal fragment has been reported in several instances. The observations have concerned a fragment of mediocentric shape, sometimes with satellites, and occasionally with satellites on both ends. The exact determination of the nature of these chromosomal fragments is very difficult or impossible, and therefore their interpretation is almost always related to clinical features.

We wish to report a case in which a $47, \mathrm{XY}$ karyotype included a mediocentric fragment; the child had degenerative stigmata which suggested partial Down's syndrome.

\section{Case Report}

Clinical data. The propositus is the second child of apparently normal parents. At birth the mother was 31 and the father 35 years. Delivery was protracted and vacuum extraction was used. The birthweight was $3085 \mathrm{~g}$. The anamnestic data show that the mother had difficulty also with the delivery of the first child, and that forceps had been used.

The last observations on our patient were carried out when he was 14 months. There was psychomotor retardation and he was at a level of only 8 months. He sat alone, but stood up only with help, and he could not walk.

At the age of 3 months he had a spastic bronchitis complicated by the bilateral bronchopneumonia.

Physical examination showed normal height and weight for his age. The following degenerative stigmata were observed: mild muscular hypotonia, broad face with a slight hypertelorism, and bilateral epicanthal folds. The palate was high arched, the mouth was wide, but the tongue did not protrude. The ears were in the normal position. The chest was symmetrical; there was a small umbilical hernia. The lengths of both humeri and femori were shorter when compared with the lower part of the extremities. Fig. 1 shows the striking genu valgum. The external genitalia were normal and the testes were in situ.

Biochemical examinations of blood: Ca $10.4 \mathrm{mg} . / 100$ ml., P 5.6 mg./100 ml., Cl 632 mg./100 ml., Na 231 mg./

Received 15 December 1969.
$100 \mathrm{ml}$., K $20.6 \mathrm{mg} . / 100 \mathrm{ml}$., alkaline phosphatase 3.9 Bodansky units. Cholesterol was $260 \mathrm{mg} . / 100 \mathrm{ml}$., and protein-bound iodine was $7 \cdot 1 \gamma \%$. The levels of valine and $\alpha$-aminobutyric acid in urine were increased.

Chest $x$-rays showed no abnormality of heart and lungs. Skeletal maturation was adequate for the patient's age.

Cytogenetic examination. The chromosome analyses were performed on preparations of peripheral blood cultures. The number of chromosomes was counted in 30 mitoses. In all metaphase plates an extra chromosomal mediocentric fragment was identified. In some of them we were able to detect the presence of satellites, in others this fragment was found in association with acrocentric chromosomes.

The karyotypes of both parents did not have any numerical or structural abnormality.

Dermatoglyphs. The qualitative patterns of dermatoglyphs are shown in Fig. 3. The quantitative traits show decreased total number of finger-tip ridges (84), perhaps of a hereditary nature (father has a total number of 99 ridges). The values of atd angles are $65^{\circ}$ for the right palm and $60^{\circ}$ for the left one.

Professor Penrose's comment: 'There is nothing specially noticeable about the prints: the patterns could be part of a normal variation.'

\section{Discussion}

The first group of reported cases are those without any specific clinical features relating to hitherto known chromosomal syndromes. Borges and Wald (1963) reported a small satellited fragment in a case of true hermaphroditism with predominantly masculine external genitalia. The fragment was transmitted from the father and the second sib, who also had hermaphroditism and an apparently normal karyotype. Other minute chromosomes were reported by Smith et al. (1965) in a boy with oligospermia, by Stevenson, Patterson, and Goodman (1966) in a mentally retarded girl with multiple anomalies, and by Pfeiffer, Diekmann, and Buchner (1967) in a case of primordial dwarfism. 


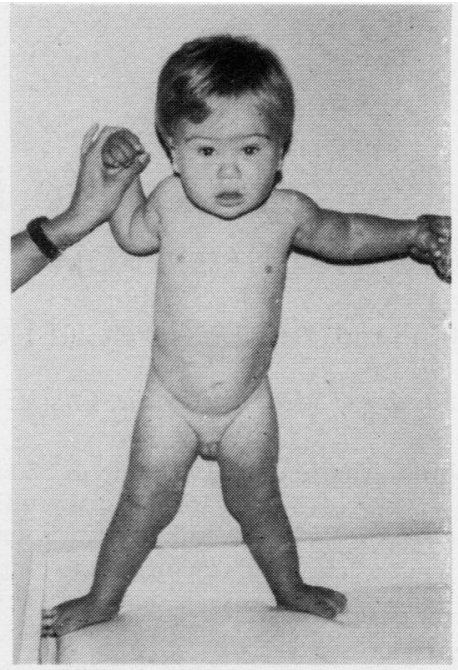

(a)

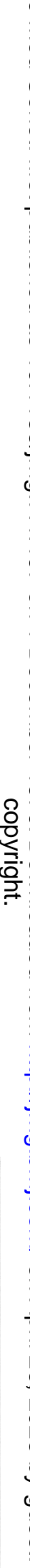

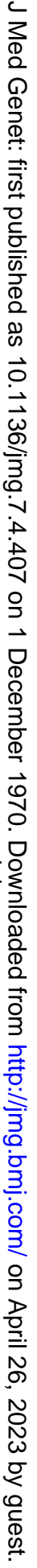

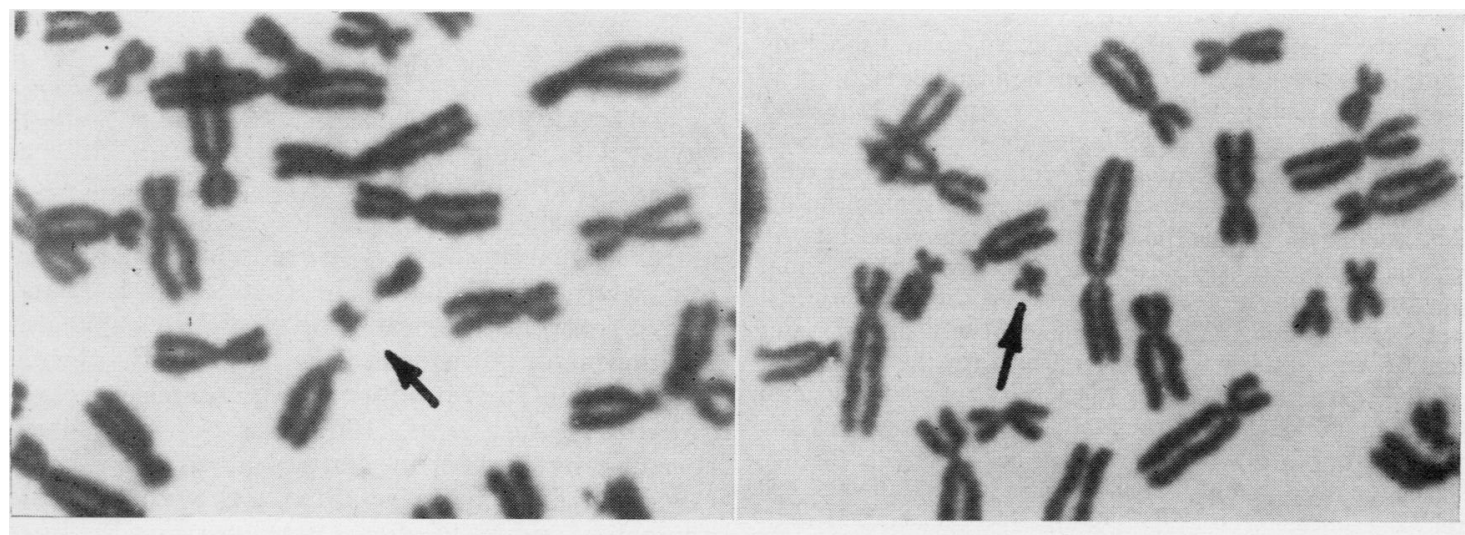

(a)

(b)

Fig. 2a and b. Details of two different metaphase plates. The extra chromosomal fragments are arrowed. (a) A typical association of acrocentric chromosomes, including the fragment. 


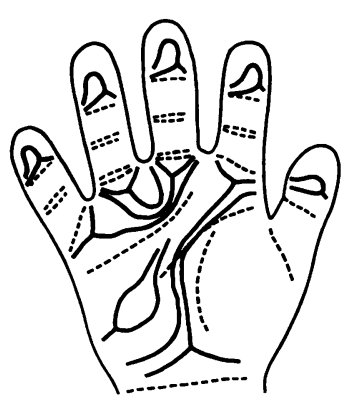

a

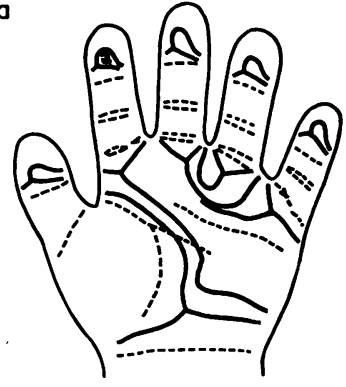

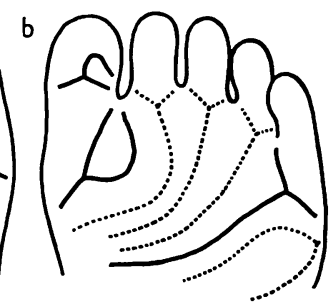

Fig. 3. Dermatoglyph showing main lines of the patient's palms and soles.

The second group contains those cases reported by Frøland, Holst, and Terslev (1963), Gustavson, Atkins, and Patricks (1964), Taft, Dodge, and Atkins (1965), Tamburro and Johnson (1966), and by Ishmael and Laurence (1968). These authors thought that the divergent chromosome was an extra chromosome 18 and thus partial trisomy $\mathbf{E}$. Their patients had some features commonly found in Edwards' syndrome (low IQ, hypertonia, spasticity, etc.).

In the third group are cases where partial features of Down's sydrome were seen and the minute chromosome was thought to be chromosome G. This group includes the cases of Ilbery, Lee, and Winn (1961), Migeon, Kaufmann, and Young (1962), Dent, Edwards, and Delhanty (1963), and Mukerjee and Burdette (1966).

In our case the clinical features together with chromosomal findings, i.e. the presence of satellites and the association with other acrocentric chromo- somes, strongly suggest the abnormal chromosome to be chromosome $\mathrm{G}$.

\section{Summary}

In an infant who showed microsymptoms of Down's syndrome cytogenetic examination detected an extra chromosomal fragment. Regarding the presence of satellites and the typical association with acrocentric chromosomes, it has been thought of as an aberrant chromosome $G$, and the karyotype as a partial trisomy $\mathrm{G}$.

We are grateful to Professor Jiřina Čižková for the support and interest in our work, to Professor L. S. Penrose for the comment on dermatoglyphs, and to Mr. A. J. Lee for the dermatoglyph drawings.

\section{REFERENCES}

Borges, W. H., and Wald, N. (1963). A diminutive satellited chromosome in a father and in one of two true hermaphrodite progeny. Fournal of Pediatrics, 63, 474-415.

Dent, T., Edwards, J. H., and Delhanty, J. D. A. (1963). A partial mongol. Lancet, 2, 484-487.

Frøland, A., Holst, G., and Terslev, E. (1963). Multiple anomalies associated with an extra small autosome. Cytogenetics, 2, 99-106.

Gustavson, K. H., Atkins, L., and Patricks, I. (1964). Diverse chromosomal anomalies in two siblings. Acta Paediatrica (Uppsala), 53, 371-387.

Ilbery, P. L. T., Lee, C. W. G., and Winn, S. M. (1961). Incomplete trisomy in a mongoloid child exhibiting minimal stigmata. Medical Fournal of Australia, 2, 182-184.

Ishmael, J., and Laurence, K. M. (1968). An extra small metacentric chromosome in a mentally retarded boy. Fournal of Medical Genetics, 5, 335-340.

Migeon, B. R., Kaufmann, B. N., and Young, W. J. (1962). A chromosome abnormality with fragment in a paramongol child. Bulletin of the Fohns Hopkins Hospital, 111, 221-229.

Mukerjee, D., and Burdette, W. J. (1966). A familial minute isochromosome. American fournal of Human Genetics, 18, 62-69.

Pfeiffer, R. A., Diekmann, L., and Buchner, Th. (1967). Familial occurrence of a small metacentric extra chromosome with satellites on both ends. Annales de Génétique, 10, 124-130.

Smith, K. D., Steinberger, E., Steinberger, A., and Perloff, W. H. (1965). A familial centric chromosome fragment. Cytogenetics, 4, 219-226.

Stevenson, R. E., Patterson, R. B., and Goodman, H. O. (1966). Possible autosomal isochromosome in a malformed child. American fournal of Diseases of Children, 111, 327-332.

Taft, P. D., Dodge, P. R., and Atkins, L. (1965). Mental retardation and multiple congenital anomalies. American fournal of Diseases of Children, 109, 554-557.

Tamburro, R. F., and Johnson, C. E. (1966). An extra small metacentric chromosome in a female child. Fournal of Medical Genetics, 3, 295-297. 